\title{
Outcomes of elective head and neck confirmed or suspected cancer surgery during the COVID-19 pandemic
}

\author{
Sabrina Brar ${ }^{1}\left[\right.$ Enyi Ofo ${ }^{1} \cdot$ Nicholas Hyde $^{2} \cdot$ Dae Kim $^{1} \cdot$ Tunde Odutoye $^{1} \cdot$ David Allin $^{1} \cdot$ Aleix Rovira $^{1}$
}

Received: 27 June 2020 / Accepted: 4 July 2020 / Published online: 15 July 2020

(c) The Author(s) 2020

\begin{abstract}
Purpose To analyse the complication outcomes of COVID-19 negative patients undergoing elective head and neck surgery during the COVID-19 pandemic.

Methods This was a retrospective case review of all patients undergoing elective head and neck surgery for confirmed or suspected head and neck cancer.

Results There were no mortalities recorded in the cohort of patients analysed. At 30 days, pulmonary complications had occurred in 4 patients (9\%). None of these were related to COVID infection.

Conclusion With careful pre-operative screening of patients for COVID-19 and post-operative care in a COVID-19 clean ward, head and neck surgery can proceed safely during the epidemic. This data could help to minimise delay in treatment by allowing a greater number of elective head and neck cancer operations to proceed.
\end{abstract}

Keywords Head and neck surgery $\cdot$ COVID-19 $\cdot$ Coronavirus $\cdot$ Mortality

\section{Introduction}

Coronavirus (COVID-19), the novel disease caused by the severe acute respiratory syndrome coronavirus 2 (SARSCoV-2), was declared a pandemic by the World Health Organisation in March 2020 [1]. There have been over $7,250,000$ confirmed cases worldwide and to date, over 400,000 people have died as a result of the disease [1]. The disease outbreak has tested the resilience of global healthcare services.

Our institution is a tertiary centre for head and neck cancer and documented its first coronavirus deaths on the 12th March 2020. Within 8 days, the total number of patient deaths in this hospital accounted for $1 / 5$ th of all deaths recorded in London [2]. By mid-April, London was the worst hit region in the United Kingdom, recording the highest age-adjusted mortality rate in the country ( 85.7 per 100,000 deaths related to COVID-19) [3].

Sabrina Brar

sb1816@my.bristol.ac.uk

1 ENT Department, St George's University Hospital, London, UK

2 Oral and Maxillofacial Surgery Department, St George's University Hospital, London, UK
In response to the pandemic, a dramatic and unprecedented change to clinical practice has necessarily been implemented. Primarily, this has been to increase inpatient capacity to meet the demands created by the acute surge in COVID-19 patients, many of whom require ventilated beds in an intensive care setting. This requires staff re-allocation away from normal surgical duties. Furthermore, early published data have suggested that the 30-day mortality and morbidity were significantly higher in patients undergoing both elective and emergency surgery when SARSCoV-2 infection was confirmed perioperatively [4]. For these reasons, NHS England and other professional bodies worldwide have issued guidance on how best to prioritise patients undergoing surgery during this time. As a result of the above, our institution acted to limit all 'non-essential' surgery, thereby minimising the risk of in-hospital COVID19 transmission, as well as any post-operative pulmonary complications that may ensue [5-7].

Sadly, delaying elective surgery will have a significant negative impact on both patients and healthcare systems worldwide. Whilst many elective operations can be delayed, the treatment of many head and neck cancers cannot be safely deferred. Any delay in such patients' cancer must be weighed against associated increased morbidity and mortality. 
Herein, we present the complication outcomes of patients undergoing elective head and neck surgery for confirmed or suspected cancer during the COVID-19 pandemic in a hospital treating a high volume of COVID-19 patients. This study reports on the 30-day mortality and morbidity of elective head and neck surgery, including both the rate of pulmonary and non-COVID-19-related complications. This data provides a baseline from which hospitals can plan their postpandemic surgical recovery. There has been only one similar small study published in the literature that investigated the outcome of three patients undergoing elective head and neck surgery during the COVID-19 pandemic [8].

\section{Methods}

\section{Study design}

This was a retrospective case review of all patients undergoing elective head and neck surgery for confirmed or suspected head and neck cancer.

\section{Study population}

All patients undergoing elective head and neck surgery for confirmed or suspected cancer at our institution over an 8-week period (23rd March-20th May 2020) were included in this study. The hospital's Standard Operative Procedure (SOP) (dated 1st May 2020) stated that all patients undergoing elective surgery had to confirm if they were unwell, exhibited any COVID-19 symptoms or had been in close contact with a person with symptoms. Patients were advised to self-isolate for 14 days prior to surgery. A nasopharyngeal swab was taken $48 \mathrm{~h}$ prior to admission. On the day of surgery, patients underwent chest radiography (CXR), which was reported by a radiologist. Perioperatively, patients remained in a designated COVID 'green' part of the hospital, where all patients had a COVID-negative swab and were asymptomatic for COVID symptoms. Prior to 1st May 2020, there was no formal SOP but our unit's practice was similar.

\section{Exclusion criteria}

Patients undergoing procedures under local anaesthetic, trauma/emergency surgery or other otolaryngological procedures were not included.

\section{Variables}

The primary outcome measure was 30-day mortality of patients undergoing surgery. The secondary outcome measure was 30-day morbidity including pulmonary and other post-operative complications. Pulmonary complications were defined as atelectasis, pneumonia, acute respiratory distress syndrome and post-operative ventilation (non-invasive/invasive) that was not expected as part of the normal post-operative course. Post-operative complications were graded using the head and neck modified Clavien-Dindo classification [8]. Only routine anonymised data were collected.

\section{Results}

A total of 47 patients were included in the final analysis. Patient demographics including age, sex, co-morbidities and ASA (American Society of Anaesthesiologists physical status classification) were recorded [9] (Table 1). Pre-surgery COVID symptoms and status were analysed-no patients reported any pre-operative COVID symptoms (defined as cough and/or fever, shortness of breath and myalgia). Accordingly, all of the patients were assumed to be COVID19 negative; this was supported by a negative swab in $81 \%$ of the patients (Table 2). The remaining 19\% of patients were operated on prior to our hospital's SOP, which stated that a swab and CXR must be taken prior to surgery.

There were no mortalities recorded in the cohort of patients analysed (Table 1). At 30 days, pulmonary complications had occurred in four patients $(9 \%)$. None of these were related to COVID infection (Table 3). Three of the patients who suffered pulmonary complications were male; they were all over the age of 50 with at least one co-morbidity that included being a current/ex-smoker.

30-day morbidity for non-pulmonary complications was recorded in eight patients (17\%) (Table 4). They were equally distributed between males and females. $88 \%$ of the patients were aged 30-69.

\section{Discussion}

The COVID-19 pandemic has drastically changed clinical practice worldwide and the delivery of routine elective surgery has been disrupted to protect patients and healthcare workers. It has been estimated that $28,404,603$ operations globally could be postponed due to the COVID-19 pandemic [10]. Currently, there is no vaccination or cure for COVID19. Results from one recent English study revealed that only $6.78 \%$ of the general population were positive for COVID-19 antibodies and so it is likely that COVID-19 will continue to be problematic for the foreseeable future [11]. Key considerations must be taken to allow for the resumption of elective services to help address the significant backlog of surgical work and potential harm to patients waiting for their delayed treatment [12]. 
Table 1 Baseline demographic characteristics

\begin{tabular}{|c|c|c|c|c|}
\hline & Patient numbers & $\begin{array}{l}\text { 30-Day mortal- } \\
\text { ity (no. of } \\
\text { patients) }\end{array}$ & $\begin{array}{l}\text { 30-Day pulmonary } \\
\text { complications (no. of } \\
\text { patients) }\end{array}$ & $\begin{array}{l}\text { 30-Day mor- } \\
\text { bidity (no. of } \\
\text { patients) }\end{array}$ \\
\hline Total patients & 47 & 0 & $4(9 \%)$ & $8(17 \%)$ \\
\hline \multicolumn{5}{|l|}{ Sex } \\
\hline Male & $31(66 \%)$ & 0 & $3(6 \%)$ & $4(9 \%)$ \\
\hline Female & $16(34 \%)$ & 0 & $1(2 \%)$ & $4(9 \%)$ \\
\hline \multicolumn{5}{|l|}{ Age (years) } \\
\hline$<29$ & $2(4 \%)$ & 0 & 0 & 0 \\
\hline $30-49$ & $13(28 \%)$ & 0 & 0 & $3(6 \%)$ \\
\hline $50-69$ & $24(51 \%)$ & 0 & $3(6 \%)$ & $4(9 \%)$ \\
\hline$>70$ & $8(17 \%)$ & 0 & $1(2 \%)$ & $1(2 \%)$ \\
\hline \multicolumn{5}{|l|}{ Number of co-morbidities } \\
\hline 0 & $13(28 \%)$ & 0 & 0 & $3(6 \%)$ \\
\hline 1 & $15(32 \%)$ & 0 & $2(4 \%)$ & $2(4 \%)$ \\
\hline 2 or more & $19(40 \%)$ & 0 & $2(4 \%)$ & $3(6 \%)$ \\
\hline \multicolumn{5}{|l|}{ ASA grade } \\
\hline 1 & $13(28 \%)$ & 0 & 0 & $1(2 \%)$ \\
\hline 2 & $26(55 \%)$ & 0 & $2(4 \%)$ & $6(13 \%)$ \\
\hline 3 & $6(13 \%)$ & 0 & $1(2 \%)$ & $1(2 \%)$ \\
\hline 4 & $2(4 \%)$ & 0 & $1(2 \%)$ & 0 \\
\hline \multicolumn{5}{|l|}{ Symptoms at admission } \\
\hline None & $47(100 \%)$ & 0 & 0 & 0 \\
\hline Symptoms & 0 & 0 & 0 & 0 \\
\hline \multicolumn{5}{|l|}{ Cancer stage } \\
\hline Diagnostic surgery & $19(40 \%)$ & 0 & $1(2 \%)$ & $4(9 \%)$ \\
\hline 1 & $11(23 \%)$ & 0 & $1(2 \%)$ & 0 \\
\hline 2 & $4(9 \%)$ & 0 & $1(2 \%)$ & $1(2 \%)$ \\
\hline 3 & $2(4 \%)$ & 0 & 0 & 0 \\
\hline 4 & $11(23 \%)$ & 0 & $1(2 \%)$ & $3(6 \%)$ \\
\hline \multicolumn{5}{|l|}{ Operation } \\
\hline Panendoscopy \pm tonsillectomy \pm dental extractions & $17(36 \%)$ & 0 & $1(2 \%)$ & $4(8 \%)$ \\
\hline Wide local excision tongue/buccal mucosa \pm neck dissection & $11(23 \%)$ & 0 & $2(4 \%)$ & $1(2 \%)$ \\
\hline Nasal biopsy \pm debulking & $7(15 \%)$ & 0 & $1(2 \%)$ & \\
\hline Total thyroidectomy + selective neck dissection & $4(9 \%)$ & 0 & & $1(2 \%)$ \\
\hline Parotidectomy \pm neck dissection & $3(6 \%)$ & 0 & & \\
\hline Trans oral robotic surgery + selective neck dissection & $1(2 \%)$ & 0 & & $1(2 \%)$ \\
\hline Selective neck dissection & $1(2 \%)$ & 0 & & \\
\hline Excision lymph node & $1(2 \%)$ & 0 & & \\
\hline Major head and neck resection with free flap reconstruction & $1(2 \%)$ & 0 & & $1(2 \%)$ \\
\hline Right partial maxillectomy + obturator insertion & $1(2 \%)$ & 0 & & \\
\hline
\end{tabular}

Table 2 Negative COVID-19 status confirmed with nasal swab and/ or CXR

\begin{tabular}{lc}
\hline COVID-19 status & Total patients \\
\hline Negative (swab and CXR) & $22(47 \%)$ \\
Negative (swab or CXR) & $38(81 \%)$ \\
No swab or CXR & $9(19 \%)$ \\
\hline
\end{tabular}

Initial analysis of patients undergoing elective surgery that were asymptomatic and not known to be infected with SARS-CoV-2 in China during the COVID-19 pandemic suggested that surgery may exacerbate COVID-19 disease progression. Lei et al. [13] demonstrated a mortality rate of $20.5 \%$ in patients undergoing various planned operations and all patients went on to develop pneumonia. 30-day mortality and morbidity have been found to be significantly higher 
Table 3 30-day pulmonary complications following elective head and neck surgery

\begin{tabular}{|c|c|c|c|c|c|c|c|}
\hline Sex & Age & Co-morbidities & ASA & $\begin{array}{l}\text { COVID-19 } \\
\text { negative } \\
\text { swab }\end{array}$ & Normal CXR & Operation & Pulmonary complication \\
\hline M & 54 & Asthma, HTN, ex-smoker, COPD & 3 & Nil & Nil & $\begin{array}{l}\text { Wide local excision tongue, } \\
\text { selective neck dissection, radial } \\
\text { forearm free flap }\end{array}$ & Bacterial pneumonia \\
\hline M & 68 & Ex-smoker & 2 & Nil & Yes & $\begin{array}{l}\text { Wide local excision buccal } \\
\text { mucosa, selective neck dissec- } \\
\text { tion }\end{array}$ & Atelectasis \\
\hline $\mathrm{F}$ & 72 & Smoker, OA, HTN, COPD & 4 & Negative (2) & Yes & $\begin{array}{l}\text { Endoscopic debulking of left } \\
\text { sinonasal mucosal melanoma }\end{array}$ & Bacterial pneumonia \\
\hline M & 62 & Smoker & 2 & Negative (1) & Yes & Panendoscopy & $\begin{array}{l}\text { Saturations dropped } \\
88-92 \text { (non-diagnosed } \\
\text { COPD) }\end{array}$ \\
\hline
\end{tabular}

Table 4 30-day post-operative complications following elective head and neck surgery

\begin{tabular}{|c|c|c|c|c|c|c|}
\hline Sex & Age & Co-morbidities & ASA & $\begin{array}{l}\text { COVID-19 Nega- } \\
\text { tive swab }\end{array}$ & Normal CXR & $\begin{array}{l}\text { Post-operative complication (using the head and } \\
\text { neck modified Clavien-Dindo classification [8] }\end{array}$ \\
\hline M & 67 & T2DM, ex-smoker & 3 & Negative (2) & Normal & I \\
\hline M & 68 & Ex-smoker & 2 & Nil & Normal & II \\
\hline M & 43 & Nil & 1 & Negative (1) & Nil & II \\
\hline $\mathrm{F}$ & 46 & Nil & 2 & Nil & Nil & II \\
\hline M & 70 & $\mathrm{AF}$ & 2 & Negative (1) & Nil & III \\
\hline $\mathrm{F}$ & 37 & Nil & 2 & Negative (1) & Normal & I \\
\hline $\mathrm{F}$ & 67 & $\begin{array}{l}\text { Smoker, GORD, high } \\
\text { cholesterol }\end{array}$ & 2 & Nil & Normal & II \\
\hline M & 54 & Ex-smoker, HTN & 2 & Negative (1) & Normal & II \\
\hline
\end{tabular}

(23.7\% mortality and $50.9 \%$ pulmonary complications) in patients undergoing surgery (elective and emergency), when SARS-CoV-2 infection is confirmed perioperatively [4]. The most vulnerable patients have been identified as males over the age of 70 with co-morbidities, those undergoing cancer or other major surgery and patients requiring emergency operations [4]. Patients with cancer are at an increased risk of contracting COVID-19 compared with non-cancer patients [14] and the rate of fatality amongst this patient cohort has been found to be $5.6 \%$ compared with $2.3 \%$ for the average population [15].

The impact of operating on non-coronavirus elective head and neck patients has not been notably analysed. However, as a result of published studies such as Lei et al. [13] and a paucity of local data regarding patient safety outcomes, thresholds for performing surgery during these times have been rightly scrutinised. This led to the NHS England guideline for the management of patients requiring surgery during the COVID-19 crisis. This document describes five priority levels and their corresponding action, to be decided by a consultant lead within each speciality [16]. At the peak of the COVID-19 pandemic, only priority level $1 \mathrm{a}, 1 \mathrm{~b}$ and 2 patients were permitted to undergo surgery nationally. This was supported by BAHNO, ENT UK and BAETS [17]. A comparable approach has been adopted by institutions in other countries such as France, USA and Australia [18-20] and has also been recommended by a consortium of international clinical trials units, member organisations of the Head and Neck Cancer International Group [21].

The multidisciplinary management of head and neck cancer patients is complex. This cohort of patients is usually older and co-morbid, often with tobacco-related respiratory diseases, and therefore has a higher risk of developing severe post-operative complications both with and without SARSCoV-2 exposure and infection [8,9]. Delaying treatment is, however, associated with disease progression and increased patient anxiety, which can negatively impact patient survival outcomes [9].

Our study analysed patient data over an 8-week period during the peak of the COVID-19 pandemic in a hospital treating a high number of patients infected with SARSCoV-2. The study identified that, in our case series, there was no 30-day mortalities related to COVID-19 or other causes in patients asymptomatic for SARS-CoV-2 
infection undergoing elective head and neck surgery. $81 \%$ of the patients were confirmed to be negative for SARSCoV-2 infection perioperatively through swab testing or CXR. The remaining 19\% did not have confirmed evidence of COVID-19 status in their documentation; however, they underwent surgery as no symptoms of COVID19 or contact with anyone with symptoms was reported pre-operatively.

Furthermore, the study did not demonstrate any notable risk of 30-day pulmonary complications-9\% of the patients analysed had a documented lung complication post-operatively. No complication was COVID-19 related; no patients tested positive for SARS-CoV-2 infection postoperatively. At the time of analysis, no patient remained in hospital following surgery. This has a significant implication for clinical practice, as it is evidence from a London teaching hospital and acute medical admission and trauma unit at the epicentre of the COVID-19 pandemic. The data can be interpreted and used to balance the risk of delaying elective surgery versus proceeding with operating on head and neck cancer patients.

\section{Study limitations}

There are limitations to recognise when interpreting the data presented in this study. Although all patients undergoing elective head and neck surgery were included, the sample size was relatively limited. Baseline patient demographics were analysed; however, ethnicity was not included. This is important because black, Asian and minority ethnic groups have been found to have a markedly higher vulnerability and risk of mortality from COVID-19 [22].

Lastly, a nasopharyngeal swab, and/or CXR was used as means of determining pre-operative SARS-CoV-2 infection status. The benefit of testing patients however relies on the accuracy of the test and current literature states that the exact sensitivity and specificity for diagnosing infection with SARS-CoV-2 in unknown [23]. The recent introduction of antibody testing may form an important part of pre-surgery assessment, in conjunction with or replacing the nasopharyngeal COVID-19 swab. Mounting an antibody response is however host-dependent and studies have shown that the average time a patient takes to seroconvert SARS-CoV-2 infection is 7-11 days [24]. Antibody testing is, therefore, not useful to determine acute infection status. Similarly, it is not yet known whether people who have been infected with and recovered from SARS-CoV-2 are fully immune from further infection; however, in combination with a nasopharyngeal swab, antibody testing could form part of the COVID-19 'pandemic suppression campaign' [24], enabling hospitals to move forward and perform surgery in the absence of a COVID-19 vaccination or cure [24].

\section{Conclusion}

This study looks at surgical 30-day mortality and morbidity rates in COVID-19 negative patients undergoing elective diagnostic and major therapeutic head and neck oncological surgery. There was no recorded mortality or post-operative COVID-19 related complications in our case series. Our results suggest that, with careful pre-operative screening of patients for COVID-19 and post-operative care in a COVID19 clean ward, head and neck surgery can proceed safely during the epidemic. This data could help to minimise the delay in treatment by allowing a greater number of elective head and neck cancer operations to proceed.

Availability of data and material The data that support the findings of this study are available from the corresponding author upon reasonable request.

\section{Compliance with ethical standards}

Conflict of interest All authors declare that they have no conflict of interest.

Open Access This article is licensed under a Creative Commons Attribution 4.0 International License, which permits use, sharing, adaptation, distribution and reproduction in any medium or format, as long as you give appropriate credit to the original author(s) and the source, provide a link to the Creative Commons licence, and indicate if changes were made. The images or other third party material in this article are included in the article's Creative Commons licence, unless indicated otherwise in a credit line to the material. If material is not included in the article's Creative Commons licence and your intended use is not permitted by statutory regulation or exceeds the permitted use, you will need to obtain permission directly from the copyright holder. To view a copy of this licence, visit http://creativecommons.org/licenses/by/4.0/.

\section{References}

1. World Health Organization (2020) WHO Timeline Covid-19. https://www.who.int/news-room/detail/27-04-2020-who-timel ine---covid-19. Accessed 13 June 2020

2. Gov.uk (2020) Coronavirus (COVID-19) cases in the UK. https $: / /$ coronavirus.data.gov.uk/\#categ ory $=$ regions $\& \mathrm{map}=$ case. Accessed 13 June 2020

3. Office for National Statistics (2020) Deaths involving COVID19 by local area and socioeconomic deprivation: deaths occurring between 1 March and 17 April 2020. https://www.ons.gov. uk/peoplepopulationandcommunity/birthsdeathsandmarriages/ deaths/bulletins/deathsinvolvingcovid19bylocalareasanddeprivat ion/deathsoccurringbetween1marchand17april. Accessed 16 June 2020

4. COVIDSurg Collaborative (2020) Mortality and pulmonary complications in patients undergoing surgery with perioperative SARS-CoV-2 infection: an international cohort study. Lancet. https://doi.org/10.1016/S0140-6736(20)31182-X 
5. COVIDSurg Collaborative (2020) Global guidance for surgical care during the COVID-19 pandemic. Br J Surg. https://doi. org/10.1002/bjs.11646

6. American College of Surgeons (2020) COVID-19: Elective Case Triage Guidelines for Surgical Care. https://www.facs.org/covid -19/clinical-guidance/elective-case. Accessed 13 June 2020

7. Stevens S (2020) Letter to Chief Executives of all NHS Trusts and Foundation Trusts. https://www.england.nhs.uk/coronavirus/wpcontent/uploads/sites/52/2020/03/urgent-next-steps-on-nhs-respo nse-to-covid-19-letter-simon-stevens.pdf. Accessed 13th June 2020

8. Hintze JM et al (2020) Mortality risk in post-operative head and neck cancer patients during the SARS-Cov2 pandemic: early experiences. Eur Arch Otorhinolaryngol. https://doi.org/10.1007/ s00405-020-0613-w

9. Monteiro E et al (2014) Assessment of the Clavien-Dindo Classification System for Complications in Head and Neck Surgery. Laryngoscope 124(12):2727-2731

10. Chaves ALF et al (2020) Emergency changes in international guidelines on treatment for head and neck cancer patients during the COVID-19 pandemic. Oral Oncol. https://doi.org/10.1016/j. oraloncology.2020.104734

11. COVIDSurg Collaborative (2020) Elective surgery cancellations due to the COVID-19 pandemic: global predictive modelling to inform surgical recovery plans. Br J Surg. https://doi.org/10.1002/ bjs. 11746

12. Office for National Statistics.(2020) Coronavirus (COVID-19) Infection Survey pilot: England, 12 June 2020. https://www.ons. gov.uk/peoplepopulationandcommunity/healthandsocialcare/ conditionsanddiseases/bulletins/coronaviruscovid19infectionsur veypilot/12june2020. Accessed 16 June 2020

13. Royal College of Surgeons of England. (2020) Recovery of surgical services during and after COVID-19. https://www.rcseng.ac. uk/coronavirus/recovery-of-surgical-services/. Accessed 13 June 2020

14. Lei S et al (2020) Clinical characteristics and outcomes of patients undergoing surgeries during the incubation period of COVID-19 infection. Lancet 21:100331

15. Yu J, Ouyang W, Chua MLK, Xie C (2020) SARS-CoV-2 transmission in patients with cancer at a Tertiary Care Hospital in Wuhan. China. JAMA Oncol. https://doi.org/10.1001/jamao ncol.2020.0980

16. Wu Z, McGoogan JM (2020) Characteristics of and important lessons from the coronavirus disease 2019 (COVID-19) outbreak in China: summary of a report of 72314 cases from the Chinese Center for Disease Control and Prevention. JAMA 323:1239

17. Royal College of Surgeons of England. (2020) Coronavirus (COVID-19). https://www.rcseng.ac.uk/coronavirus/. Accessed 13 June 2020

18. ENT UK. Clinical guide to surgical prioritisation during the coronavirus pandemic (ENT specific). https://www.entuk.org/clini cal-guide-surgical-prioritisation-during-coronavirus-pandemicent-specific. Accessed 16 June 2020

19. Fakhry N, Schultz P, Morinière S, Breuskin I, Bozec A, Vergez S et al (2020) French consensus on management of head and neck cancer surgery during COVID-19 pandemic. Eur Ann Otorhinolaryngol Head Neck Dis 137(3):159-160

20. Head MA, Consortium NSTG, members: C, Maniakas A, Jozaghi Y, Zafereo ME et al (2020) Head and neck surgical oncology in the time of a pandemic: subsite-specific triage guidelines during the COVID-19 pandemic. Head Neck 42(6):1194-1201

21. Yuen E, Fote G, Horwich P, Nguyen SA, Patel R, Davies J et al (2020) Head and neck cancer care in the COVID-19 pandemic: a brief update. Oral Oncol 105:104738

22. Mehanna H, Hardman JC, Shenson JA, Abou-Foul AK, Topf MC, AlFalasi M et al (2020) Recommendations for head and neck surgical oncology practice in a setting of acute severe resource constraint during the COVID-19 pandemic: an international consensus. Lancet Oncol. https://doi.org/10.1016/S1470-2045(20)30334 $-\mathrm{X}$

23. Razaq A et al (2020) BAME COVID-19 DEATHS - What do we know? Tapid Data \& Evidence Review. CEBM. https://www. cebm.net/covid-19/bame-covid-19-deaths-what-do-we-knowrapid-data-evidence-review/. Accessed 15 June 2020

24. Zitek T (2020) The appropriate use of testing for COVID-19. West J Emerg Med 21(3):470-472

25. Al-Muharraqi MA (2020) Testing recommendation for COVID-19 (SARS-CoV-2) in patients planned for surgery-continuing the service and 'suppressing' the pandemic. BR J Oral Maxillofac Surg 58(5):503-505

Publisher's Note Springer Nature remains neutral with regard to jurisdictional claims in published maps and institutional affiliations. 